\title{
El II Concilio de Zaragoza (592) y las últimas repercusiones de la crisis arriana en la Hispania visigoda
}

\author{
Federico-Mario Beltrán torreira *
}

La celebración del III Concilio de Toledo -cuyo MCD aniversario acabamos de conmemorar- significó, por encima incluso del solemne refrendo a la previa conversión visigoda, el fin del tradicional distanciamiento entre las autoridades bárbaras y el clero hispano-romano. Un distanciamiento convertido en abierta hostilidad durante el reinado de Leovigildo a causa de su política religiosa, y de la actitud favorable al rebelde Hermenegildo ( $y$ en suma a Bizancio), de buena parte del episcopado católico. En ese sentido, el clima de "unanimidad y paz» que el reinado de Recaredo vino a inaugurar, y cuya mejor expresión es el propio III Concilio toledano, se caracterizaría por una progresiva integración de la Iglesia en el aparato de la nueva monarquía. Hasta el punto de alcanzarse una práctica simbiosis, ideológica como real, entre ambos poderes, que sólo la invasión musulmana pudo truncar ${ }^{1}$.

Con ser esto cierto, no lo es menos que durante los primeros tiempos del "Nuevo Orden" visigodo católico se mantuvieron aún posturas por completo reticentes a aceptar el cambio de situación. Sin duda, las más llamativas, y suficientemente estudiadas, son la serie de conjuras político-religiosas que, ya antes de la celebración del Concilio, protagoni-

\section{* Universidad Complutense de Madrid.}

' La bibliografia sobre el III Concilio de Toledo es abundantisima. Remitimos a los estudios generales de K. SchafERDiEK, Die Kirche in der Reichen der Westgoten und Suewen bis zur Errichtung der westgotischen katholischen Staatskirche. Berlin 1967, págs. 205233; y J. ORlandis, Historia de los concilios de la España romana y visigoda. Pamplona 1986, págs. 204-226. 
zaron diversos elementos eclesiásticos y aristocráticos visigodos, en un desesperado intento por impedir el abandono de la fe de sus padres ${ }^{2}$. Las revueltas, inconexas en el tiempo y en el espacio (Mérida en 588, Toledo y Septimania en 589), fracason sin excepción, como también sucederia con la efectuada inmediatamente después del concilio por el dux Argimundo. Aunque en este caso la motivación religiosa no esté desde luego tan clara ${ }^{3}$.

Mayor interés tiene, sin embargo, analizar la posiura adoptada por buena parte de los hispano-romanos -en particular por su portavoz, el clero- ante el hecho de la conversión de los visigodos. Postura en absoluto caracterizada por el perdón y la tolerancia, como tratan de hacernos creer las obras historiográficas cortesanas y las mismas actas del III Concilio de Toledo. El "borrón y cuenta nueva" que en el ámbito ideológico oficial supuso la magna reunión de mayo de 589 , no parece que se correspondiera en suma con la real actitud - al menos a corto plazode ninguna de las dos partes. En ese sentido, el análisis de las actas del II Concilio de Zaragoza, celebrado el 1 de noviembre de 592, como de otros documentos anejos al mismo, constituye un elemento de excepcional interés para calibrar la pervivencia, en el seno de la comunidad hispano-romana, de una actitud contraria a aceptar incondicionalmente a los conversos de la herejía ${ }^{4}$.

La propia elección de Zaragoza es en sí un índice revelador de lo que venimos diciendo. Pese a tratarse de un sínodo provincial de la Tarraconense, es altamente probable que se designara no a la sede metropolitana - Tarragona - sino a aquélla como lugar de reunión, a causa de los mismos asuntos a tratar, sin excepción, relacionados con el arrianismo. El mal recuerdo que en la sede de Zaragoza habia dejado la política de unificación religiosa de Leovigildo, y más en concreto su relativo éxito (hasta el punto de lograr la apostasía del obispo Vicente), constituia sin duda una afrenta que era necesario vengar ${ }^{5}$. El sinodo se

2 Sobre estas conjuras, E. A. THOMPson, Los godos en España. Madrid 1971, páginas. 121-124; J. Orlandis, La España visigótica. Madrid, págs. 113-114, y L. A. Garcia Moreno, "Las invasiones y la época visigoda", Romanismo y germanismo. El despertar de los pueblos hispánicos (sigios v-x). Barcelona 1981, págs. 323-324.

Ultimamente a favor de tal posibilidad, M. C. DIAZ Y DiAZ, "Introducción general", San Isidoro de Sevilla: Etimologias. Madrid 1982, pág. 28, y R. Collins, Early Medieval Spain. Unity in diversity (400-1000). Londres 1983, pág. 57. Sobre Argimundo, añádase, L. A. García Moreno, Prosopografía del Reino visigodo de Toledo. Salamanca 1974, págs. 34 y 35.

${ }^{4}$ J. Orlandis, Historia de los concilios..., págs. 235-241.

Sobre Vicente, L. A. Garcia Moreno, obra citada, pág. 205, y L. Garcia Iglesias, Zaragoza, ciudad visigoda. Zaragoza 1919, págs. 65-66. 
convertía así en ocasión de oro no sólo para borrar cualquier sospecha sobre el, a veces, discutible comportamiento del episcopado católico en los pasados años de persecución, sino también para obtener justa satisfacción al agravio recibido por tan rancia comunidad cristiana.

La ausencia de los antiguos obispos arrianos de la Tarraconense, Ugnas de Barcelona y Froisclo de Tortosa (seguramente no deseada por éstos), y el propio rigorismo de los cánones aprobados, serán por lo tanto las notas dominantes en la reunión. La desconfianza, cuando no la abierta mal fe, debieron sin duda caracterizar a la mayoría de los allí presentes ${ }^{6}$.

Los tres cánones del sínodo se ocupan, respectivamente, de la recepción en el seno de la Iglesia del antiguo clero arriano, de sus reliquias y de las basilicas consagradas por los obispos de la secta. En cuanto al primer tema, se superaba con creces lo dictaminado por el III Concilio de Toledo (exigencia sólo del celibato), al someter a los presbíteros conversos a una nueva - y sin duda humillante- ordenación. En caso de negarse, perderían, pura y simplemente, su condición clerical ${ }^{7}$.

El segundo canon obligaba a los sacerdotes de las diferentes diócesis a entregar a sus obispos, so pena de excomunión, las reliquias procedentes de los antiguos lugares del culto arriano, tras lo cual se las sometería a la prueba del fuego -igne probentur- para comprobar, se ha dicho, su veracidad ${ }^{8}$. La medida resulta explicable en el contexto inmediatamente posterior al reinado de Leovigildo, cuya política religiosa había incluido desde 580 (y siempre con el objeto de ganarse a los católicos) la incautación de ciertas reliquias y su traslado a los templos arrianos, así como - especialmente - el decidido apoyo a la veneración de aquellas que estuvieran aún en manos ortodoxas por parte de los herejes $^{9}$. La confusión, todavia existente en 592 respecto a este asunto,

6 K. Schaferdiek, M. C. Diaz y Diaz y J. Orlandis, obra citada, págs. 221-224, $26-28$ y 237-238, respectivamente. Sobre los dos obispos citados, L. A. Garcia Moreno, obra citada, págs. 202-203 y 209 .

Conc. Tol. III, 5, y Con. Caes. II, 1. J. VIVEs, Concilios visigóticos e hispano-romanos. Barcelona-Madrid 1963, págs. 126-127 y 154, respectivamente. J. ORLANDIS, “Problemas canónicos en torno a la conversión de los visigodos al catolicismo", AHDE, 32 (1962), paginas 313-314.

${ }^{8}$ Conc. Caes. II, 2. J. Vives, obra citada, pág. 154. J. OrLandis, obra citada, pág. 310.

"J. ORLANDIS, "El Arrianismo visigodo tardio", CHE, 65-66 (1981), págs. 17-18. De todas formas, los arrianos nunca se distinguieron en lo más mínimo de sus oponentes católicos en su fe por las reliquias. J. ZEILLER, Les origenes chrétiennes dans les provinces dannubiennes de l'Empire romain. París 1918, págs. 511 y ss., y M. MESLIN, Les ariens d'Occident (335-430). París1967, págs. 394 y ss. Y lo mismo cabe decir de su falta de 
habria querido zanjarse ahora mediante esta drástica medida. No obstante, habida cuenta el rigorismo general a la asamblea, como el origen mismo de las reliquias puestas en cuestión, resulta altamente verosímil pensar que con la irase igne probentur no se está aludiendo a una ordalia, sino simplemente a una destrucción sistemática y deliberada ${ }^{10}$. Destrucción que sabemos sufrió en esos años el conjunto de la literatura visigoda arriana por el mismo método ${ }^{11}$.

En cuanto al tercer y último canon resulta sin duda el más interesante, por abordar una problemática (la de las basilicas arrianas) sobre la que estamos en particular bien informados para el caso de Zaragoza. En linea con la dureza de los otros dos cánones, se decidió que la consagraciones de los antiguos templos de la secta realizadas por los obispos conversos no fueran válidas (aunque se hubiesen realizado ya sub nomine catholicae fidei), en tanto éstos no hubieran recibido la bendición de manos de un prelado católico ${ }^{12}$. Postura que, de hecho, implicaba negar validez a las ordenaciones mismas de los obispos conversos, como ya había sucedido con aquellas recibidas por los sacerdotes. No puede extrañar, por lo tanto, la ausencia de los ya citados Ugnas y Froisclo de una asamblea que les negaba su propia condición pastoral. A ojos de los reunidos se trata de aspirantes a obispos, cuando no simplemente de obispos en precario.

Respecto a las basilicas, el Concilio de Zaragoza, como ya antes hiciera el III Concilio de Toledo, aludía naturalmente a las procedentes de manos arrianas, arrebatadas en su día (mayoritariamente en época de Leovigildo) a los católicos. ${ }^{13}$. Reintegradas ahora a la verdadera Iglesia, era necesario proceder a su nueva consagración. Cosa lógica, si se tiene

repugnancia, a la hora de venerar las que estaban en manos "romanas". Gregorlo de Touns, Mirac. Mart 1,11. P. L. t. LXXI, cols. 923-925; LMS 110. (Missa de trasnlatione corporis sancti Saturnini episcopi). M. FEROTIN, Le "Liber Mozarabicus Sacramentorum" et les manuscrits mozarabes. Paris 1912, cols. 461-463. P. BATTIFOL, "Un sourvenir du royaume wisigoth de Tolouse (412-507), dans une messe mozarabe". Études de liturge et d'archéologie chrétiennes. Paris 1919, págs. 180-192.

10 Así, J. TEJada Y Ramiro, Colección de cánones $y$ de todos los concilios de la lglesia de España y de América, t. II. Madrid 1850, pág. 130, y A. IGLESIA FERREIRos, "El proceso del conde Bera y el problema de las ordalías", AHDE, 51 (1981), págs. 79-80

J. ORLANDIS, "Problemas canónicos...", págs. 308-309.

12 Conc. Caes. II, 3. J. Vives, obra citada, pág. 154. Vide supra N. 7. Hay que tener en cuenta además que, como los herejes de toda época, los arrianos creian ser los verdaderos católicos, designando a sus oponentes como "herejes homousianos", y a su fe como "religión romana".

${ }^{1 / 3}$ Conc. Tol. III, 9. J. Vives, obra citada, pág. 127. Sobre estas incautaciones, J. Or. LANDIS, obra citada, pág. 308. 
en cuenta que la herejia se consideraba una "mancha» o "enfermedad" que resultaba obligado "limpiar", "curar» ${ }^{14}$.

A tono con esto mismo, y como ya antes se apuntó, el caso de Zaragoza puede analizarse mejor que el de las restantes sedes de la Tarraconense, gracias a ciertos documentos litúrgicos-hagiográficos de gran interés, que sin embargo no han solido tenerse en cuenta a la hora de analizar la problemática del presente sinodo. En concreto, nos referimos a la Missa sancte Engretie (vel XVIII martyrum cesaraugustanorum, y a la Passio sanctorum martyrum unnumerabilium cesaraugustanorum, conservadas en el Liber Mozarabicus Sacramentorum y en el «Pasionario Hispánico", respectivamente. La data de ambos documentos coincide, con toda probabilidad, con la celebración del II Concilio de Zaragoza ${ }^{15}$.

Sobre la primera de estas piezas cabe decir que, en efecto, fue compuesta significativamente para celebrar la reconciliación de la importante basílica de Santa Engracia, entregada al culto de la herejía por el obispo apóstata Vicente en época de Leovigildo. Aunque la Missa no contenga una fecha explícita, parece lógico pensar que debió oficiarse públicamente el domingo 2 de noviembre de 592, como precioso colofón a la asamblea zaragozana, y coincidiendo con la reconciliación de la propia basilica. Acto éste que, al menos canónicamente, tan sólo debía realizarse en domingo, como es sabido ${ }^{16}$.

En cuanto a la obra en sí, se caracterizaba por un tono virulentamente antiarriano que, en el fondo, lo es también antigótico, a pesar de la aparente moderación de ciertas expresiones. A diferencia de la idílica imagen transmitida por San Leandro en su "Homilia" al II Concilio de Toledo, no deja de echarse en cara a los visigodos su oscuro pasado

${ }^{14}$ San Gregorio Magno, Dial. III, 30. PL, t. LXXVII, cols. 288-289, y Gregorio de Tours, De glor. mart. 40. Pl, t. LXXI, col. 741. Sobre la ceremonia de consagración, M. FEROTIN, Le "Liber Ordinum" en usage dans l'Église wisigothique et mozarabe d'Espagne du cinquieme au onzième siècle. París 1904, cols. 511ss; P. DE PUNIET, "Dedicace des églises", $D A C L$, t. 4/1. París, 1920, cols. 374-405; J. Vives, "Consagraciones de iglesias visigodas en domingo", AST, 15 (1942), pág. 257, y P. BAYART, "Consécrations des églises", DDC, t. 4, Paris 1949, cols. 258-267.

15 LMS, 72. M. FEROTIN, Le "Liber Mozarabicus Sacramentorum"..., col. 272, y Pas. Hisp. 52. A. Fabrega Grau, Pasionario Hispánico, Il: Texto. Madrid-Barcelona 1955, páginas 371.378.

$16 \mathrm{~J}$. VIVES, obra citada, págs. 257-264. Para otros autores la fecha de reconciliación pudo haber sido el lunes 3 de noviembre, coincidiendo con la instauración de la nueva fiesta de los Innumerables: véanse notas 17, 18 y 20 . Sobre la basilica de Santa Engracia, L. Garcia Iglesias, obra citada, págs. 25-26. 
religioso, como su reciente actitud persecutora ${ }^{17}$. Actitud que sale a colación una y otra vez, siquiera de forma velada, mediante las continuas alusiones a los desmanes del gobernador Daciano ${ }^{18}$.

Respecto a la Passio no puede ser desde luego muy posterior al II Concilio de Zaragoza, como parecen indicarlo ciertos párrafos alusivos a la reconciliación de la basílica ${ }^{19}$. Incluso puede aventurarse que se leyera ya públicamente el 3 de noviembre de 592, pues tal fue el día elegido por la iglesia zaragozana para conmemorar, a partir de entonces, la fiesta de los Innumerables ${ }^{20}$.

La Passio traza, por lo demás, un bien sombrío retrato del ya citado praeses Daciano, personaje de historicidad dudosa al que gran número de obras hagiográficas (entroncadas todas con la llamada Passio de communi), atribuyen la mayoria de los martirios ocurridos en Hispania bajo Diocleciano. Visto todo lo anterior, no sería una locura sospechar que, al menos subliminalmente, los anómnimos autores de la Passio y

17 LMS 72: "Diem hunc, dilectissimi fratres, in quo desiderata nobis advecta sunt gaudia, in quo Sanctorum hic quiescentium preter consuetas excubias nova curamus persolvere festa solemniter celebrantes, tota in Christo exultatione latemur. Ipsique reddamus vota cum gaudiis, qui prestitit letitiam mestis: quia quod dudum vecors temere abstulit Gothica quasi sub fide gentilitas, restituit eorum divino inspiramine ad Christum conversa fidelitas. Que ut ex oleastri radice frondose olive virgulta conscendens, odoriferos Christo exhibet fructus: et licet fieri non fide sed violentia infidelitate direptum, fideli tamen est devotione sacra insedere vocitatum. Erat siquidem tunc gentis eius fides ficta, nunc firma; tunc falsa, nunc mera: et qui habuit cum divisionis minoratione errorem, nunc exhibet cum distinctione nominum unitatis integritatem. Nunc quod dissensionis veneno corruptor veritatis ignarem gentem olim fecerat, ut suavissimi thymiamatis perfectio credulitate nunc flagrat". Cit. cols. 272-273.

18 Ibidem, cols. 273-275. Véase nota 21. En general, sobre esta Missa, A. LAMBERT, "La famille de Saint Braulio et l'expansion de la Règle de Jean de Biclar", Universidad, 10 (1933), págs. 74-75, y C. Garcia Rooriguez, El culto a los santos en la España romana y visigoda. Madrid 1966, págs. 330-332.

19 Pas. Hisp. 52, 12-14: "En cineres Innumerabilium sanctorum martyrum oculis nostris ascipientes, summa cum exultatione veneramur, eorumque triunfos, letantes, conpatiendo iungimur. Aulam denique ob eorum honorem onmipotenti Domino consecravimus, ut quibus tua sevities nomen maluit funditus extirpare christianorum, populus tripudiando non sinit eorum festivis gaudiis adsociare... Nos autem, quod presentium sanctorum martyrum meritis fidei sancte catholice unitas adsociavit, annuo cursu eorum festis adque triumfis congaudea. mus, cum summa devotione excubies celebremus, ut eorum meritis rite participari merea. mur». Cit. págs. 377-378. Véase nota 16.

20 Sobre esta obra, A. FABREga Grau, obra citada, I: Estudio. Madrid-Barcelona 1953, págs. 168-174, y C. Garcia Rodriguez, obra citada, págs. 329 y 332-333. La objeción de aquél -ibídem, pág. 170, nota 11-. a A. LAMBERT -obra citada, pág. 75-, en el sentido de que la consagración de la basílica no pudo realizarse el día 3 , por ser lunes, puede evitarse si se acepta nuestra fecha del 2 de noviembre. En todo caso, hay que señalar que pese a lo ordenado canónicamente, las consagraciones no se realizaban siempre en domingo. Conc. Caes. III, 1. J. VIVES, Concilios visigóticos..., pág. 476. 
de la Missa, así como sus destinatarios, los feligreses de Zaragoza, estuvieran pensando realmente en los desgraciados y, todavía recientes, tiempos de Leovigildo. Es decir, que asimilaran al legendario perseguidor romano con el monarca visigodo ${ }^{21}$.

Sea como fuere, es también posible que la citada Passio de communi, fuente de la de los Innumerables e igualmente redactada en Zaragoza en torno al 592, pudiera añadirse al elenco de documentos que venimos tratando. Al menos asi parece indicarlo un pasaje en el que se narra la cremación y posterior dispersión de los restos de los mártires ordenadas por Daciano para impedir su culto. Al mencionar el fracaso de tal medida, opinan algunos autores, se estaria también aludiendo a la renovada piedad a las reliquias tras la devolución de la basílica de Santa Engracia a los católicos ${ }^{22}$.

Desconocemos, por desgracia, el autor o autores de todas estas piezas. La tradicional atribución de la Passio innumerabilium a San Braulio hace tiempo que se ha demostrado falsa ${ }^{23}$. Lo único que cabe, pues afirmar es que todas estas obras fueron compuestas al calor del II Concilio de Zaragoza, integrando quizá una colección, si no oficial, si al menos oficiosa. Contaron desde luego con la aprobación de los allí reunidos, especialmente con la del metropolitano Artemio, y también, como es obvio, con la del entonces obispo de la ciudad, Máximo ${ }^{24}$.

Años más tarde, tanto Ugnas como Froisclo aparecian firmando ya las actas del II Concilio de Barcelona (599) junto a sus compañeros hispano-romanos. Sin duda, la rápida vuelta a la normalidad vino favorecida por la propia renovación del episcopado de la Tarraconense, plasmada en el abandono de su característica hostilidad hacia los antiguos conver-

${ }^{21}$ A. Fabrega Grau, págs. 256-259, y B. DE Gaiffier, "Sub Daciano Praeside. Étude des quelques Passions espagnoles", Analecta Bollandiana, 72 (1954), págs. 378-383. En concreto, sobre Daciano, A. H. JONES y J. R. MARTINDALE, The prosopographi of the Later Roman Empire, 1: A. D. 260-395. Cambrigde 1971, pág. 244.

22 Así, A. Fabrega Grau, B. de Gaiffier y C. Garcia Rodriguez, obra citada, págs. 7475, 384-385 y 333-334, respectivamente. Sobre la Passio de communi. A. FABrega Grau, obra citada, págs. 68-75, 257-259. Niegan su real existencia, B. DE GAIfFIER y C. Garcia Rodriguez, obra citada, págs. 382-384 y 251-253, 311, respectivamente. A favor de FA. BREGA y de la temprana redacción del "Pasionario Hispánico", M. C. DiAZ y DiAZ, "Note for a chronology of the Pasionario Hispánico", Classical Folia, 24 (1970), págs. 28-45.

${ }^{23}$ C. H. LYNCH y P. GaLINDO, San Braulio, obispo de Zaragoza (631-651). Su vida y sus obras. Madrid 1950, págs 279-284.

${ }^{24}$ Sobre ambos, L. A. Garcia Moreno, obra citada, págs. 198 y 205-206, repectivamente. 
sos. Mas también, seguramente, fueron éstos los que con su ortodoxia supieron ganarse el respeto de sus colegas ${ }^{25}$. Del mismo modo que sus hermanos de raza -el obispo Juan de Gerona y el príncipe Recaredolo habian ya conseguido en la propia asamblea zaragozana ${ }^{26}$.

${ }^{25}$ M. C. Díaz y Diaz, “Introducción general...", pág. 28, y J. ORLandis, Historia de los concilios..., págs. 238 y 244 .

${ }^{26}$ Sobre Juan de Biclaro, L. A. Garcia Moreno, obra citada, págs. 213-214, Aparte de la muy positiva mención al rey en el II Concilio de Zaragoza ("glorioso y santísimo"), está la propia elaboración de la conocida epistola de Fisco Barcinonensi. Acto que presupone la aceptación del nuevo papel político otorgado a la Iglesia por el III Concilio de Toledo (canon 18), aunque no necesariamente, como se ha visto, el abandono de las reticencias de carácter religioso. Sobre la epistola, compuesta el 4 de noviembre de 592, y por lo tanto muy verosimilmente antes de que los padres conciliares regresaran a sus diócesis, J. ORLANDIS, obra citada, págs. 239-241. 